\title{
A Study to Explore the Safety and Professional Challenges Faced by the Field
}

\section{Journalists in Pakistan}

\author{
* Ayesha Siddiqua, Lecturer \\ ** Dr. Faiza Latif, Assistant Professor (Corresponding Author) \\ *** Dr. Imran Muslim, Assistant Professor
}

\begin{abstract}
Field journalists in Pakistan who have covered violent conflicts especially in the wake of Karachi, Baluchistan, and former FATA conflicts have repeatedly staked their physical, emotional, and financial security while fulfilling their journalistic responsibilities. The study at hand is majorly aimed at exploring the reactions of the field journalists in Pakistan concerning the professional and safety challenges faced by them. A purposive sample of 15 field journalists from mainstream newspapers and television channels of Pakistan was selected for conducting the qualitative in-depth interviews. The study concluded that the most frequently faced challenges by the field journalists in Pakistan included the tendency to self-censor one's content and editorial judgment; working under loosely defined safety protocols; and absence of seeking psychological help in terms of handling Post Trauma Stress Disorder (PTSD).

Keywords: Conflict Coverage; Safety of Journalists; Self-Censorship; Peace Journalism Conflict Coverage and Pakistani Media Landscape

The role of media has evolved tremendously over the period in terms of both conflict escalation and de-escalation. According to an estimate, almost one-quarter to one-third of United Nations member states are either conflict-ridden or conflict-stressed (Betz, 2011). The reasons behind modern conflicts are still widely unexplored. Conflict can include various forms of disagreements and differences which can encompass both violent and non-violent methods. Conflict can also be understood as a relationship between different groups that can be categorized for irreconcilable objectives, desires, and benefits (Mitchell, 1981).

As conflicts can be classified into international, interstate, and intra-state levels, the current study has focused on some of the intra-state conflicts of Pakistan. Intra-state conflicts include organized combat forces that are mostly capable of active resistance because of which stronger group can defeat the weaker one (Small \& Singer, 1982). Armed Resistance is a catalyst in intrastate conflicts. Intrastate conflict is usually operationalized as an armed dispute between the governmental and non-governmental entities and which leads to at least 25 conflict-related deaths in one calendar year (Wallensteen \& Sollenberg, 2011).

As violence levels increased in Pakistan during the past decade an intensified conflict situation has been witnessed in Baluchistan. The magnitude of the Baluchistan conflict which is also the largest province of Pakistan in terms of territory has been attributed to sectarian and terrorist activities that have extensively targeted certain communities especially the Hazara Community. As a result of secessionist insurgency and military operations which are underway in the province more than 22 journalists were killed in Baluchistan between 2008 and 2012 ("22 Journalists Killed in four years", 2012).
\end{abstract}

\footnotetext{
* Department of Mass Communication, National University of Modern Languages, Islamabad, Pakistan. Email: ayeshasiddiqua05@gmail.com

** Department of Mass Communication, Lahore College for Women University, Lahore, Pakistan. Email: faiza.latif@lcwu.edu.pk

*** Department of Mass Communication, Government College University, Faisalabad, Pakistan. Email: imranmuslim@gcuf.edu.pk
} 
A tenfold increase in violence was reported in Karachi between 2006 and 2013 (Yamin and Malik, 2014). The conflict in Karachi became extensively complex as sectarian groups and terrorists joined the conflict zone. Military operations had also been carried out in Karachi. Search operations and raids by Rangers continued in 2015 and the first few months of 2016. The Rangers policing powers were extended in Sindh in 2015 (Ali, 2015). The conflicts which surfaced in Karachi from time to time could create such huge effects that the political and economic stability of the whole of Pakistan can be put at risk (Shamim, 2018).

In 2017 number of reforms were approved by the Pakistani Parliament for merging former Federally Administered Tribal Areas (FATA) with the neighboring Khyber Pakhtunkhwa (KPK) province. Despite the extensive support for the reforms package the issue of mainstreaming FATA is still considered to be a long journey. The reforms are meant to bring the people of FATA under the constitutional umbrella by implementing the justice system, modern policing, local governmental setup, ensuring social and economic development, settlement of internally displaced people and rebuilding of war hit areas (Ali, 2018).

Media coverage of conflicts heavily relies on the information which is timely delivered through field journalists. Field journalists are expected to report conflicts without nurturing the flames of violence as the effects of media coverage can sometimes prove to be stronger than the government policies. Journalists working on conflict assignments in Pakistan are among the highly vulnerable ones. Pakistan is ranked as one of the most unsafe countries for journalists as 102 journalists were killed between 2005 and 2016 (International Federation of Journalists, 2016). The report by the International Federation of Journalists (2016) further stated that armed insurgence and sectarian violence are the major reasons for the killing of journalists.

Reporting of intra-state conflicts especially in the Pakistani media landscape where professional independence is difficult to achieve can turn out to be extremely challenging. Conflict reporting assignments in Baluchistan, Karachi, and former FATA areas of Pakistan are often conducted in the fear of abductions, torture, and other armed terrorist attacks. The risks involved in the reporting of intrastate conflicts become even more difficult to tackle when the freedom to broadcast views that are parallel to State's dominant narrative is strongly curbed. In such a situation journalist in general and on-field reporters become much more vulnerable. Journalists who have covered violent conflicts especially in the wake of Karachi and Baluchistan conflicts have repeatedly staked their physical, emotional, mental, and financial security while fulfilling their journalistic responsibilities.

Research on conflict reporting patterns is still underexplored in Pakistan. DeFaria (2015) reported that journalists in Pakistan and Mexico face a unique array of threats. Pakistan has ranked 9th on the Committee to Protect Journalist's Impunity Index (2015). This index measured the number of unsolved murders of journalists as a percentage of the total population. More than 100 media workers and journalists were killed in Pakistan from 2000 to 2014 which is one of the highest fatality rates to journalists killed in one country (IRADA, 2014). The killing of every individual journalist brings a lot of harassment and insecurity for the fellow journalists as well.

The study at hand is majorly aimed at exploring the reactions of the field journalists in Pakistan to the professional and safety challenges faced by them. The paper further attempted to explore the security protocols available to the field journalists in Pakistan along with comprehending the ways through which journalists recover from Post Trauma Stress Disorder (PTSD) after covering violent conflicts. The study is significant as it will help in analyzing the factors which are creating hurdles in the professional deliverance of journalists. The findings of the study will also help in providing policy guidelines to the media organizations especially regarding conflict coverage assignments.

\section{Peace Journalism}

Peace journalism has provided an important theoretical foundation to conflict reporting and is explained as editors' and reporters' choice of what to select for reporting and how to report it. It generates prospects for the public to develop less or non-violent reactions towards conflict (Lynch and McGoldrick, 2005, p.5). Galtung (1998) who first coined the term peace journalism observed that it has become a tradition for media to thrive on stories of violence and rifts without taking into consideration the effects of such journalistic practices on the society at large. Galtung's classification 
of conflict reporting and coverage into war and peace journalism has been divided into four major practices. War journalism relies on the apparent effects of conflict, is propaganda-oriented for exposing others' lies and concealing ours', presents voices of the elite, and depicts success as the ultimate result. Peace journalism is expected to be peace-oriented to identifying conflict construction and preventing conflict, truth-oriented for exposing untruths on the part of all sides, people-oriented concerning covering people as peacemakers, and solution-oriented to highlighting peace and solution initiatives (Lynch \& McGoldrick,2004). Galtung also accused traditional war journalism of reducing the conflict consequences to one-point agenda of defeat and victory for the involved stakeholders. He also proposed a resolution-oriented approach for media in times of conflict by covering stories in such a way that escalates the peace process and de-escalates violent aspects of the conflict (Galtung, 2002).

In a study by Jan and Khan (2011), it was asserted that " Media plays a central role in promotion of peace....peace journalism helps bridge the gap between enemies, so peacebuilding practitioners require understanding of the process of advocacy" (pp. 311-324). On the other hand, the increasing interest of scholars in comprehending conflict journalism patterns also lies in the predominantly established notion that journalism is war and conflict-oriented especially in countries like Pakistan which are driven by many internal conflicts (Rehman and Eijaz, 2015).

\section{Research Questions}

RQ1-How did media professionals deal with professional challenges especially about restrictions on their freedom of expression?

RQ2-What types of safety trainings are available to field journalists in Pakistan?

RQ3- How field journalists recover from Post Trauma Stress Disorder after covering violent incidents?

\section{Methodology}

The study is exploratory and employed a qualitative method of in-depth interviews for investigating the research questions. Interviews help comprehend the story behind respondents' experiences. Interviews are most appropriate in cases where not much is known about the phenomenon under study and where in-depth information is required from participants. Qualitative research interviews seek to cover both factual and meaning levels (Kvale, 1996). The Snow-ball technique of non-probability sampling was used for selecting the respondents as a result of which 15 field journalists working for the mainstream newspapers and television channels from Karachi, Baluchistan, and former FATA gave their concern for the interviews. The criteria for selecting the journalists included direct field experience of covering conflicts related to Karachi, Baluchistan, and former FATA. A list of questions was developed for conducting the interviews and investigating the research questions. The interviews were conducted via phone and skype. The identification information of the respondents was not mentioned to protect the identity of the respondents. The audio files were recorded, and notes were also taken during the interviews.

\section{Findings}

\section{RQ1-How did media professionals deal with professional challenges especially regarding} restrictions on their freedom of expression?

Most respondents agreed that the attempts to restrict freedom of expression are handled through imposing self-censorship measures. In the pre-FATA merger scenario, respondents agreed that the enforcement of narrowly defined Sharia laws also hampered the free flow of information. The on and off peace negotiations between the government and the Taliban's usually lead to severe selfcensorship on the part of the journalists as any objective reporting was termed as hazardous for the peace process. Respondents further stated that the media organizations often dictated the journalists that they should not criticize the state's narrative and practice self-censorship especially in stories related to sectarian and religious extremism. A senior field journalist from former FATA stated that "stories related to religious extremism are extremely sensitive and as Pakistani journalists we practice extreme caution while reporting such stories because our own lives are at great risk".

The effects of curtailing freedom of expression were also seen on the editorial judgment as certain newsworthy stories were dropped in favor of less important statement-oriented stories. The freedom of expression was hampered in such a way that sometimes the objectivity of the news story was compromised. A journalist from Baluchistan stated that after the sensitive operations in an area 
"you are accompanied by Public Relations Officers or Media Managers of the government and military organizations which is another form of indirect censorship".

Respondents agreed that resisting the pressure often leads to a drastic drop in advertising revenues because of which most media owners prefer to refrain from challenging the status quo even in the presence of authentic information. A field journalist from Karachi asserted that "the uncertainty surrounding media industry often leads to strict measures of self-censorship both on the part of the individual journalist and also on the part of the media owners".

Most of the respondents agreed that although editorial policies dictated from the newsrooms were considered equally important but, on the ground, actual observation was a major decisive factor for a field journalist working in the conflict zone. A field journalist from Karachi asserted that "reporter is the best judge in scenarios of live conflict reporting". Managing the flow of information and personal emotions were also ranked as determining factors in live stories by the respondents. Another field journalist from Karachi who is also a bomb attack survivor asserted that "handling of emotions is the most crucial and difficult part of live reporting in case of a violent incident".

Respondents asserted that the reasons for not broadcasting selective information included life threats to field journalists, cameramen, and technical staff along with damaging channel premises. The majority of the respondents termed statements released by Inter-Services Public Relations (media wing of Armed Forces of Pakistan) along with information released through certain WhatsApp groups of Frontier Corps in Baluchistan as the reliable and safe way of access to information. A field journalist from Quetta emphasized that information from all stakeholders should be incorporated in the story. Some of the respondents also suggested that journalism psychology must be integrated into mass communication curriculum to equip reporters for handling conflict reporting assignments.

Respondents also said that although the primary job of a reporter is to report facts as objectively as possible but this role becomes more complex and difficult to handle when it comes to conflict reporting assignments. The majority of the field journalists strongly asserted that they have frequently committed and revised information for the sake of not accelerating violence. A senior field journalist from Quetta agreed that " reporters repeatedly found themselves struck between state and anti-state actors" but their obvious choice is to rely on the version of reality provided by the state. Respondents considered political parties as equally intolerant of opposing views. Another field journalist from Quetta asserted that "the pressure of political labeling of opponents is frequently witnessed by journalists". Respondents agreed that the Government dictates the media for a particular "slant" which serves its interests similarly the law enforcement agencies do not want "critical" stories to be done regarding their operations. This scenario ultimately leaves little choice for the field journalists especially in the wake of current media downsizing trends.

\section{RQ2- What types of safety trainings are available to field journalists in Pakistan?}

Respondents agreed that field journalists hardly receive any formal safety pieces of training from their employers. Although some of the mainstream channels including Geo and Express-News used to provide some basic journalistic trainings to their employees but this practice has also become extinct with time as channels are more concerned with saving resources and logistics. Strengthening the professional excellence and safety of their employees does not even rank on the least priority of the media owners. Reporters agreed that along with the media owners state is also oblivious to the safety of journalists. A journalist from Karachi asserted that field journalists face all sorts of threats from terrorist groups, armed wings of political entities and from certain fractions of the State.

Respondents from Karachi, Baluchistan, and former FATA agreed that no training programs are offered to the filed journalists in Pakistan before sending them to conflict zones. Due to a lack of formal trainings reporters also commit negligence to safety measures while covering violent incidents. A field journalist from Quetta asserted that field journalists turn out to be the most vulnerable individuals in violent conflicts as "they are expected to report continuously and objectively from the front lines while risking their lives tremendously".

Respondents also agreed that most of the news channels in Pakistan lack the formal safety protocols regarding their employees in general and field journalists covering violent conflicts in specific. Instead of devising formal safety protocols, some media channels have developed general safety and security guidelines for the sake of face-saving. A majority of reporters from Karachi agreed that although a general understanding prevails in the news channels' management regarding safety 
protocols of journalists but not many precedents of coordinated efforts are available as media conglomerates have greater interests in their commercial profits in comparison to the safety of their employees. A field journalist from former FATA asserted that the availability of "safety protocols for provision of life and health insurance policies differ from one media employer to another".

A field journalist from Karachi ranked the "efficient response of the law enforcement personal as a determining factor in ensuring the safety of field reporters". He recalled a blast attack that took place in Quetta in which the timely decision of an SHO regarding dispersing the crowd from the blast site saved many innocent lives as the area was hit by a second blast within few minutes of the first blast. Field journalists from former FATA and Baluchistan asserted that the ideas of peace journalism can only be practiced if the journalists are given space and freedom from the state institutions.

Thus, majority of the journalists agreed that field journalists in Pakistan work under either none or very loosely defined safety protocols. The TV news channels also lack any well-defined Standard Operating Procedures regarding the safety protocols of journalists.

\section{RQ3- How field journalists recover from Post Trauma Stress Disorder after covering violent incidents?}

A field journalist from Karachi considered the "safety and security of family as a major psychological distress" in instances of covering terror attacks. She admitted that gory details of attack and violence "haunt you for many following days and nights" but majorly it is the optimistic and encouraging company of colleagues and family which works as an effective therapy. A senior filed journalist from Quetta while recalling the Bolan medical complex blast said that he along with his team was among the early response who reached the blast site. He painfully recalled that it was one of the most difficult reporting assignments as there were "scattered human parts all around". He admitted that at times "I feel like quitting this field of journalism because of the immense psychological pressures". A Karachi based reporter said that he learned his lesson of practicing acute caution after suffering a deep bullet injury during a reporting assignment. In Baluchistan and former FATA journalists felt most vulnerable in cases of threats that they receive from both state and anti-state actors along with strong surveillance of their movements. Respondents also agreed that anxiety and apprehension hit hard in case a fellow reporter is abducted or killed. In most of the cases, respondents agreed that they did not seek any professional psychological counseling rather relied heavily on the personal support circle for reducing or handling Post Trauma Stress Disorder (PTSD).

\section{Discussion \& Conclusion}

The role of journalism in supporting social, economic, and political systems is widely acknowledged (Sparrow, 2006; Cook, 2006) which further entails that journalists in general and field journalists in particular need to have a safe and free environment to perform their diverse roles in the society. Peace journalism has provided an important theoretical foundation to conflict reporting and is explained as editors' and reporters' choice of what to select for reporting and how to report it. It generates prospects for the public to develop less or non-violent reactions towards conflict (Lynch and McGoldrick, 2005, p.5). The study strengthened the literature generated by Lynch and McGoldrick (2005) which proposed that reporters constantly make and change decisions about reporting and reliance on elite sources also increases in times of conflict. Respondents agreed the information generated through state actors is heavily relied on in case of covering conflicts even if confronting credible information is available. The study was explorative as the amount of synchronized academic literature on the professional and safety challenges faced by filed journalists in Pakistan was scarce. The study concluded that the most frequently faced challenges by the field journalists in Pakistan included the tendency to self-censor one's content and editorial judgment; working under loosely defined safety protocols; and absence of seeking psychological help in terms of handling Post Trauma Stress Disorder. Practicing independent journalism in Pakistan has become extremely challenging in the current times when the journalists are struck between the state and anti-state actors along with gratifying the commercial interests of the media owners. Most of the respondents agreed that although editorial policies dictated from the newsrooms were considered equally important but, on the ground, actual observation was a major decisive factor for a reporter working in the conflict zone. The state of available safety trainings was declared highly unsatisfactory. The study also concluded that in most 
of the cases respondents did not seek any professional psychological counseling for handling Post Trauma Stress Disorder (PTSD).

Thus, the increasing interest of scholars in comprehending conflict journalism patterns lies in the predominantly established notion that journalism is war and conflict-oriented especially in countries like Pakistan which are driven by many internal conflicts (Rehman and Eijaz, 2015). The findings of Jan and Khan (2011) were also validated to a certain extent that the media professionals and journalists in Pakistan are sensitized about the importance of peace journalism but at the same time ideas of peace journalism can be fully translated by not only educating the journalists but also through sensitizing the state policymakers in the relevant areas where intersection of conflict and media is bound to take place.

In the light of the findings, some of the recommendations included that journalists should be sensitized about the repercussions of self-censorship and compromising their emotional well-being. The Job security of journalists in Pakistan needs to be governed by effective labor laws along with improving the state of available safety protocols.

\section{References}

Ali, I. (2018). Mainstreaming Pakistan's federally administered tribal areas. Special Report United States Institute of Peace. Retrieved from www. usip. Org/sites/default/files/2018 03/sr-421 mainstreaming/Pakistan-federally administered-tribal-areas. Pdf

Ali, I. (2015, Dec 29). Rangers claim to have arrested 4,074 suspects in Karachi 2015. Dawn. Retrieved from https://www.dawn.com/news/1229193

Betz, M. (2011). Conflict sensitive journalism: Moving towards a holistic framework. Committee to Protect Journalists. (2015, Oct 8). Getting Away with Murder. Retrieved from https://cpj.org/ reports/2015/10/impunity-index-getting-away-with-murder.php

Cook, T (2006). The News Media as a Political Institution: Looking Backward and Looking Forward. Political Communication, 23, 159-17న

DeFaria, D. (2015, April 27). Between conflict and stability: Journalists in Pakistan and Mexicocope with everyday threats. Retrieved from https://cpj.org/2015/04/attacks-on-the-press-journalistsin-pakistan-and-mexico-everyday-threats.php\#more

Galtung, J. (1998, September). Peace Journalism: What, Why, Who, How, When, Where. Paper presented at the workshop What are Journalists For? Taplow Court.

Galtung, J. (2002). Peace Journalism-A Challenge. Journalism and the New World Order, 2, 259-272. International Federation of Journalists. (2016). End Impunity in Pakistan. Retrieved from http://www.ifj.org/campaigns/end-impunity-2016/end-impunity-2016

IRADA (2014). Supporting safety of journalists in Pakistan: An assessment based on UNESCO's Journalists' Safety Indicators. Retrieved from https://en.unesco.org/sites/default/files/ pakistan_jsi_final_working_document_2007201_0.pdf

Jan, M., \& Khan, R. (2011). Peace Journalism and Conflict Reporting: The Case of Pakistani Media. Research Journal of South Asian Studies 26 (2): 311-324.

Kvale, S. (2006). Dominance through interviews and dialogues. Qualitative inquiry, 12(3), 480-500.

Lynch, J., \& McGoldrick, A. (2004). Peace Journalism. Hawthorn Press Stroud.

Lynch, J., and McGoldrick, A. (2005). Peace Journalism in the Holy Land. Media Development, 52 (1), 47-49.

Mitchell, C. R. (1989). The structure of international conflict. Springer.

Rahman, B., \& Eijaz, B. (2015). Pakistani Media as an Agent of Conflict or Conflict Resolution: A Case of Lal Masjid in Urdu and English Dailies. Pakistan Vision, 15(2), 238.

Shamim, S. J. (2018, February 16). Nuclear Proliferation in South Asia - Towards World War III. Retrieved from https://papers.ssrn.com/sol3/papers.cfm?abstract_id=3111513

Small, M., \& Singer, J. D. (1982). Resort to arms: International and civil wars, 1816-1980. Sage Publications, Inc.

Sparrow, B. (2006). A Research Agenda for an Institutional Media'. Political communication, 23, 145-157.

Wallensteen, P., \& Sollenberg, M. (2001). Armed Conflict, 1989-2000. Journal of Peace Research, 38(5), 629-644. 
Yamin, S., \& Malik, S. (2014). Mapping conflict trends in Pakistan. Washington, DC: United States Institute of Peace.

22 Journalists Killed in four years. (2012, July 9). Dawn. Retrieved from https://www.dawn.com/ news/732853 